\title{
Steam System Load Shedding Operational Analysis Using Dynamics Simulation of a Fertilizer Plant
}

\author{
Abdul Rahim Norman ${ }^{1, *}$, Azleen Azna Mohd Khairil Hing ${ }^{1}$, M. Azfar Md Jaafar ${ }^{1}$, and Farah Syamim Anwar ${ }^{1}$ \\ ${ }^{1}$ PETRONAS Group Technical Solutions, Process Department, 50088 Kuala Lumpur, Malaysia
}

\begin{abstract}
Steam system operation of a fertilizer plant can be complex due to high number of equipment, unavailable redundancy of steam suppliers and inter-dependency behaviour between steam users. The plant is subjected to partial or total shutdown whenever one boiler trips as both existing boilers are operating close to design capacity. Installation of an additional boiler will provide additional capacity margin in the event of one boiler trips. iCON(Symmetry) was used as the dynamic process simulation tool to establish proper management for load shedding activity with three boilers in operation. Model was developed for the integrated steam header, fuel gas and boiler feed water network. A detailed representation of the actual plant was achieved by incorporating plant hydraulics based on actual piping configurations, high fidelity equipment modelling, process control configurations, trip sequencing and operator manual interventions. This approach gives high accuracy in replicating the plant's transient behaviour for load shedding case studies. The case studies prove the three boiler arrangement is able to sustain the plant's continuous operation. An operational strategy was developed to minimize the impact of equipment trips. It is recommended to expand the model to include the process side to represent the actual plant behaviour with higher accuracy.
\end{abstract}

\section{Introduction}

Steam system operation of a fertilizer plant can be very complex, especially for a plant that has undergone multiple revamps over its lifetime. This is due to high number of equipment, unavailable redundancy of steam suppliers and inter-dependency behaviour between steam users. In the effort to minimize revenue loss due to disturbance in steam system, it is crucial to establish proper management for load shedding activity. Currently the plant operates two boilers to produce high pressure steam for users in the processing units. Since both boilers are operating close to design capacity, the plant is subject to partial or total shutdown, in case one boiler trips or undergo planned shutdown for inspection. Installation of an additional boiler will provide additional capacity margin in the event of one boiler trips. This paper will focus on the transient analysis of the steam system using dynamic simulation. The transient analysis is used to establish proper management for load shedding activity with three boilers in operation. Figure 1 illustrates the overall steam system network of the fertilizer plant.

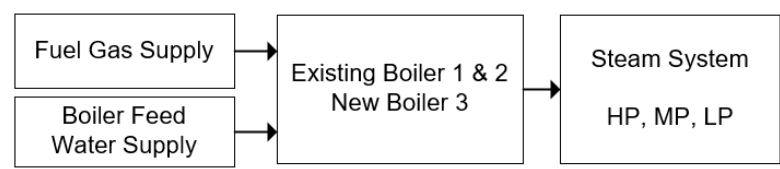

Figure 1: Overall steam system network of the fertilizer plant

\section{Methodology}

\subsection{Simulation software}

iCON (Symmetry) process simulation software is used to develop the dynamic simulation scope. Steam 97 thermodynamic property package is iCON's implementation of the 1997 standard for water and steam which is used to model the steam and boiler feed water (BFW) network system. Advanced Peng Robinson thermodynamic property package is the extension of Peng-Robinson model incorporating volume translation features. It is used to model the fuel gas network system.

\subsection{Base case simulation}

A base case simulation is developed to match existing operating conditions for a selected historical period. The selected period fulfilled the base case criteria which are stable plant operation with normal operating load and low steam imbalance operational figures. The actual operating conditions are extracted from the Plant Information Management System (PIMS). The model achieved static accuracy within $+/-2 \%$ of the instrument range.

\subsection{Equipment modelling approach}

All equipment within the model battery limits are modeled in iCON (Symmetry) with the intention to

\footnotetext{
* Corresponding author: rahim.norman $@$ petronas.com
} 
represent actual equipment conditions as close as possible [1].

\subsubsection{Piping}

Actual plant hydraulics is incorporated by extracting piping configurations (e.g. diameter, length, undulations, fittings) from available plant isometric drawings into the pipe segment unit operation in the model. Colebrook and Beggs-Brill pressure drop correlations is applied for single-phase and multi-phase fluids respectively.

\subsubsection{Steam Turbine}

The turbines are modeled using the "radial design point model" in expander unit operation. The "radial design point model" uses the software's default U/C and Q/N efficiency correction curves generated by vendor data which can be modified to match actual performance data. The $\mathrm{U} / \mathrm{C}$ and $\mathrm{Q} / \mathrm{N}$ curves are normalized against a specified design point. The design point will be based on the established base case model which includes the power, flow, efficiency, inlet density and delta P. The inlet guide vane area percentage is used to determine the steam flowrate across the turbine and is governed by the parameterization of pressure and flow relationship ( $\mathrm{K}$ value) as shown in Figure 2.

$$
\begin{gathered}
K=\text { Flow } *\left(\frac{\text { density }}{d P}\right)^{0.5} \\
K=K_{\text {ref }} * I G V \text { area }(\%) ; \text { where } K_{\text {ref }} \text { is calculated based on design point }
\end{gathered}
$$

Figure 2: K-value definition for steam turbine modelling

\subsubsection{Valve}

The actual valve properties are incorporated by extracting relevant information; for example valve characteristics, actuator stroke time, rated $\mathrm{Cv}$ curves and fluid choke curves; from the valve datasheet. All valves are assumed to be in ideal conditions, i.e. non-idealities such as stiction are not considered in the simulation model.

\subsubsection{Pump}

The high pressure BFW pumps are modelled with two pumps in series to represent the mid-stage BFW extraction. Actual pump performance head and efficiency curves are incorporated in the pump unit operation. The affinity law as shown in Figure 3 is used to create the pump performance head curve profile at varying speeds.

$$
\frac{H_{1}}{H_{2}}=\left(\frac{N_{1}}{N_{2}}\right)^{2} \quad H \text { is head, } N \text { is pump speed }
$$

Figure 3: Affinity law for head vs speed

\subsubsection{Boiler}

The boiler is represented as a simple heater unit operation with fixed pressure drop and outlet temperature. The BFW supply enters the boiler and HP steam discharge is integrated directly into the steam network system.

\subsubsection{Process Control}

The process control configuration is modelled using controller unit operation to represent the control philosophy of the network by using actual or engineering best practice PID tuning parameters. The PID control equation will be based on the generic control equation readily available in iCON (Symmetry) as illustrated in Figure 4.

$$
O P=K_{C}\left(e+\frac{1}{T_{i}} \int e d t+T_{d} \frac{d e}{d t}\right)
$$

Figure 4: Generic PID control equation [2]

The three separate network models are integrated based on the integration control philosophy considering the new boiler in place. The boiler integration control philosophy relies on the master pressure controller located at the HP steam header by automatically adjusting fuel gas and BFW flowrates to maintain HP header pressure. The $\mathrm{BFW}$ integration control philosophy relies on master pressure controller at the pump discharge outlet by automatically adjusting the power delivered by the steam turbine driver to manipulate the pump speed and maintain pump discharge pressure. Both integration control philosophies use the cascade control method.

\subsubsection{Trip Sequence}

The trip sequence is programmed using the event scheduler function in iCON (Symmetry). The trip sequence defines the sequential events following an upset condition. Emergency shutdown (ESD) interlock, controlled ramp rates and manual intervention actions are also incorporated in the dynamics model based on operator's experience input.

\section{Case Studies}

Four different case studies are defined to evaluate the system's transient behavior under different upset scenarios. The upset scenarios include both steam supply (boiler), steam user (steam turbines) and operational (boiler feed water pump) disturbances. The case studies are summarized in Table 1.

Table 1: Case studies for steam system load shedding operational analysis

\begin{tabular}{|c|c|c|}
\hline Case & Description & Objective \\
\hline 1 & One boiler trip & $\begin{array}{l}\text { Evaluate system's operability } \\
\text { for boiler ramp-up to prevent }\end{array}$ \\
\hline
\end{tabular}




\begin{tabular}{|c|l|l|}
\hline & & trip at steam network \\
\hline 2 & $\begin{array}{l}\text { Main } \\
\text { standalone } \\
\text { user trip }\end{array}$ & $\begin{array}{l}\text { Evaluate system's operability } \\
\text { with main steam turbine trip } \\
\text { which directly affects HP } \\
\text { header only. }\end{array}$ \\
\hline 3 & $\begin{array}{l}\text { Main } \\
\text { extraction user } \\
\text { trip }\end{array}$ & $\begin{array}{l}\text { Evaluate system's operability } \\
\text { with main extraction steam } \\
\text { turbine trip which directly } \\
\text { affects MP and LP steam } \\
\text { supply. }\end{array}$ \\
\hline 4 & $\begin{array}{l}\text { Accidental } \\
\text { start-up of } \\
\text { spare BFW } \\
\text { pump }\end{array}$ & $\begin{array}{l}\text { Evaluate system's operability } \\
\text { with additional pump in } \\
\text { operation to maintain BFW } \\
\text { pump discharge pressure }\end{array}$ \\
\hline
\end{tabular}

\section{Results}

\subsection{Case 1 - One boiler trip}

Case 1 results proves that the system's operability for boiler ramp-up can prevent further trips to the crucial equipment in the plant. This is achieved by automatically triggering the trip of two less crucial steam turbines whenever a boiler trip is identified. The fluctuation of steam system pressure is within allowable limits and stabilizes after several minutes as illustrated in Figure 5.
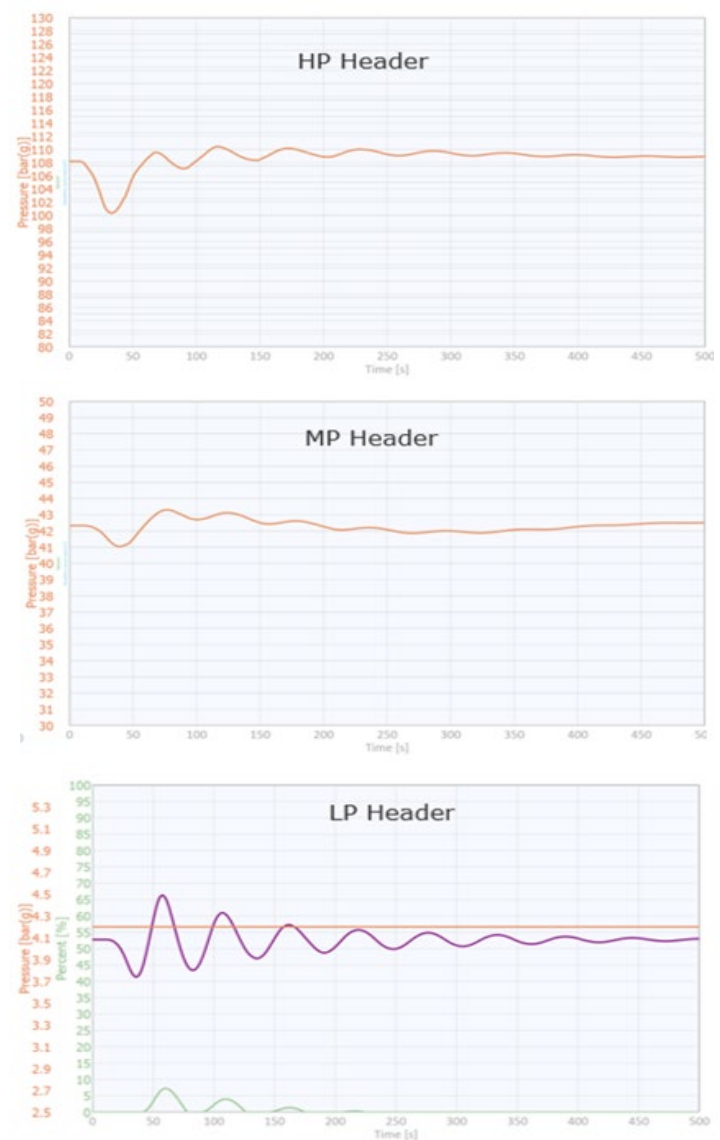

Figure 5: Trending of steam header pressures for case 1

\subsection{Case 2 - Main standalone user trip}

Case 2 results proves that the system's operability can handle the trip of the main standalone steam turbine with the current control settings. There are no direct disturbances to MP and LP steam supply when standalone steam turbine trips, therefore, the MP and LP header pressures are relatively stable as shown in Figure 6 trend charts.
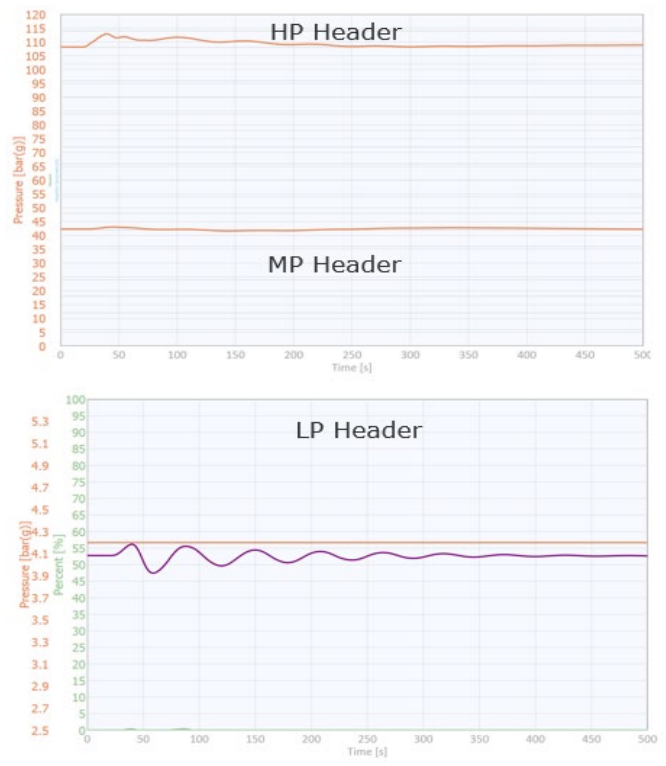

Figure 6: Trending of steam header pressures for case 2

\subsection{Case 3 - Main extraction user trip}

Case 3 calculated the lowest MP header pressure as the result of tripping the main extraction steam turbine which directly affects the steam supply to the MP and LP steam headers. The minimum MP header pressure is too low to continuously supply MP steam to reformer which will cause a major plant trip due to the steam carbon ratio disruption. Figure 7 and Figure 8 shows the high disturbances towards the steam header and BFW pump discharge pressures due to the inability of the control system to regulate steam supply efficiently for case 3 .

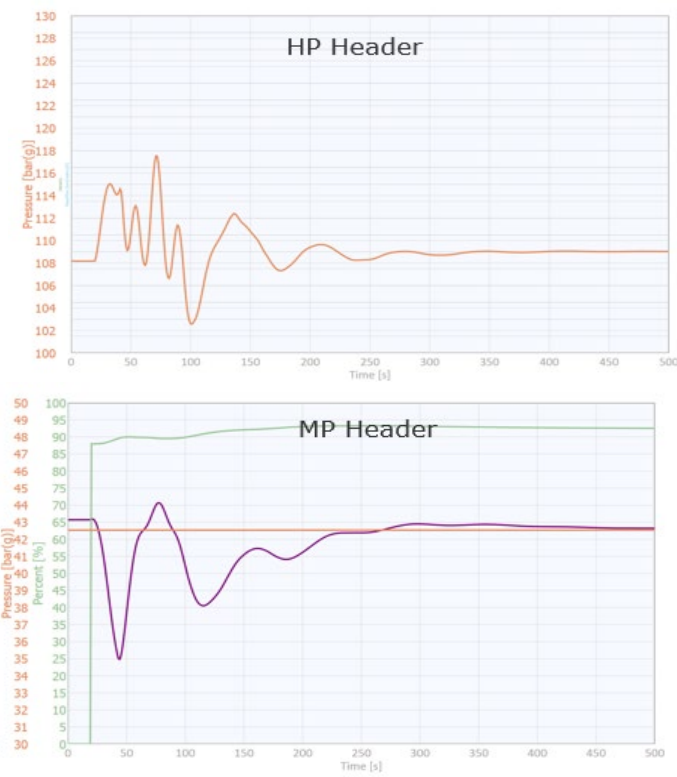

Figure 7: Trending of steam header (HP and MP) pressures for case 3 

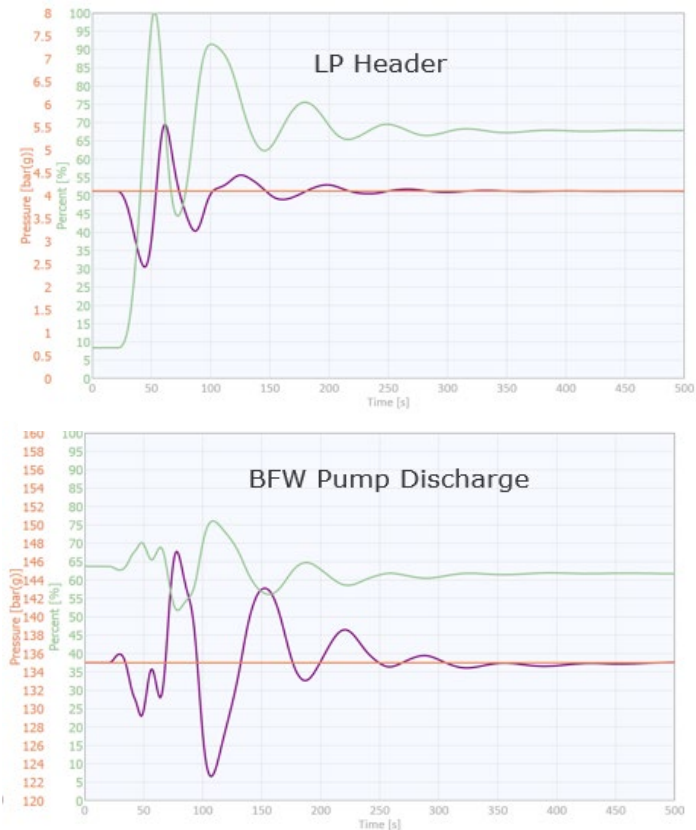

Figure 8: Trending of steam header (LP) and BFW pump discharge pressures for case 3

Case 3 simulation results is consistent with the plant's historical findings. An operational strategy was developed to prevent total plant shutdown and minimize the impact of the main extraction user trip.

\subsection{Case 4 - Accidental start-up of spare BFW pump}

Case 4 demonstrated the BFW control system can handle the transient impact of accidental spare pump start-up as shown in Figure 9. The maximum discharge line pressure observed is well below the piping design limit. Figure 10 demonstrated the fluctuations on the steam HP, MP and LP header pressures are also minimal.

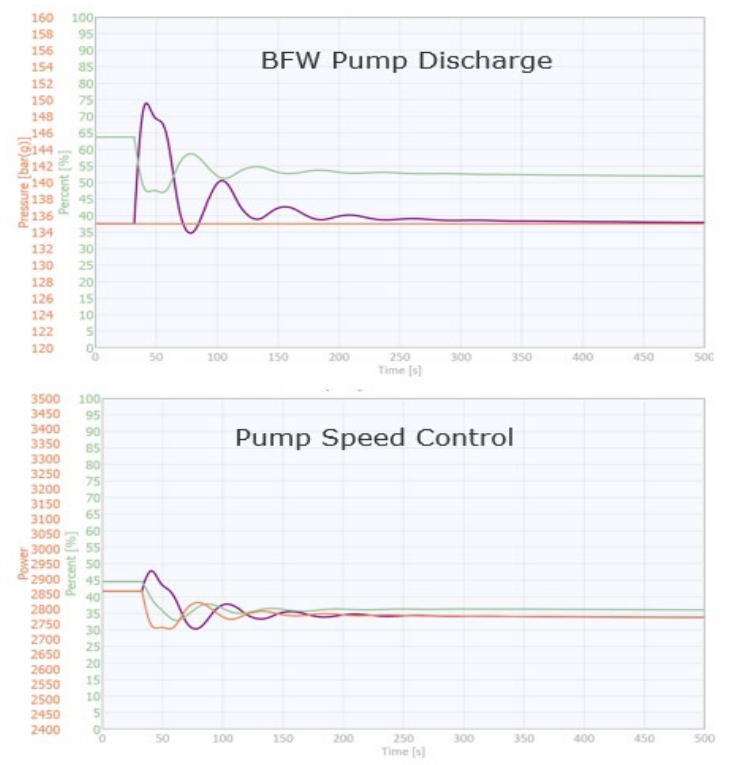

Figure 9: Trending of BFW pump discharge pressure and speed control for case 4

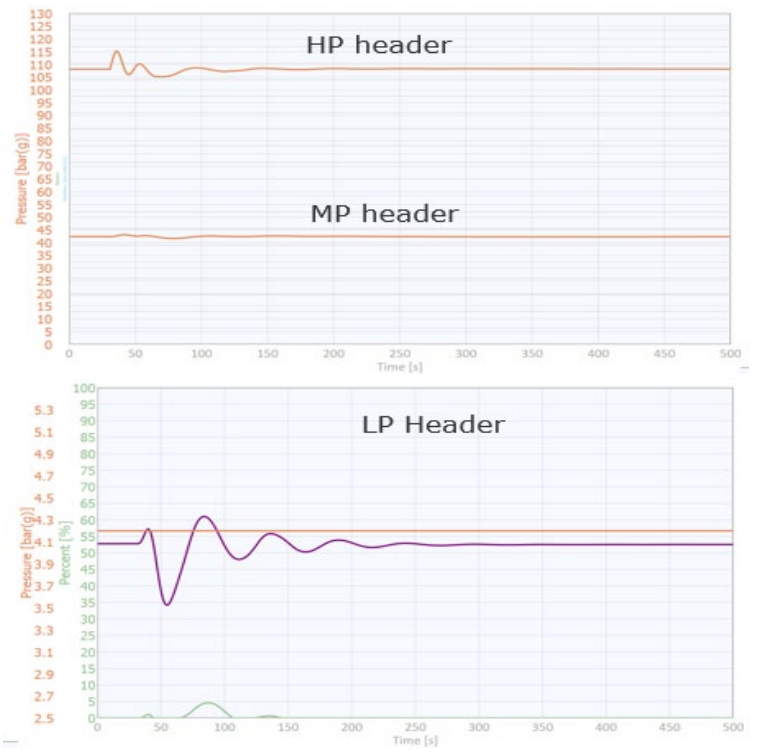

Figure 10: Trending of steam header pressures for case 4

\section{Conclusion}

The dynamic simulation study managed to meet its objective in all four cases. The supply trip case proves a three-boiler arrangement can sustain plant's continuous operation. However, case 3 demonstrates partial plant trip is inevitable which is consistent with historical plant findings. An operational strategy was developed to minimize the impact of the plant trip. The analysis of the steam system using dynamics simulation provided the project team with important recommendations to ensure correct boiler integration design and smooth plant operations.

\section{Future work}

The dynamic simulation can be further improved by modelling the boilers with high fidelity which includes the steam drum, fuel gas combustion, heat exchangers and the associated three element process control i.e. flow, pressure and level. This will further improve the accuracy of the transient analysis results.

Special thanks to project team from the fertilizer plant for making this study possible.

\section{References}

1. V.M. Group, iCON (Symmetry) User Manual, Unit Operation manual and example (2020)

2. Svrcek, W.Y., Mahoney, D.P. \& Young, B.R., A Real-Time Approach to Process Control, 2nd Edition, (Wiley, West Sussex, England, 2006) 